Abstract

\title{
Soil Erosion as an Environmental Concern ... for Everyone? ${ }^{+}$
}

\author{
Jesús Rodrigo-Comino ${ }^{1,2}$ \\ 1 Department of Physical Geography, University of Trier, 54296 Trier, Germany; rodrigo@uni-trier.de \\ 2 Soil Erosion and Degradation Research Group. Department of Geography, Valencia University, \\ Blasco Ibàñez, 28, 46010 Valencia, Spain \\ † Presented at TERRAenVISION 2019, Barcelona, 2-7 September 2019.
}

Published: 21 May 2020

\begin{abstract}
Nowadays, the scientific community is aware of the negative environmental impacts of soil erosion on ecosystem services. Soil erosion is one of the most important causes of land degradation because of its immediate influence of the most fertile topsoil parts. It is well-known that questions related to who, what, why, where and when soil erosion causes negative impacts must be considered by stakeholders and policymakers. However, why do the Sustainable Development Goals tell anything about soil erosion? In this keynote, we will try to show the importance to develop tools which can be used to assess soil erosion to obtain convincing results for stakeholders and policymakers. According to this fact, we present some studies related to in situ soil erosion measures and assessments of human perception and economical approaches. We fully agree that these kinds of studies will greatly benefit the visibility, trust and diffusion of our results. What do you think about this question? Let me know your opinion.
\end{abstract}

Keywords: soil erosion; human activities; perception; Sustainable Development Goals

(C) 2020 by the authors. Licensee MDPI, Basel, Switzerland. This article is an open access article distributed under the terms and conditions of the Creative Commons Attribution (CC BY) license (http://creativecommons.org/licenses/by/4.0/). 